\title{
ИШЕМИЧЕСКИЙ ИНСУЛЬТ И COVID-19: MЕХАНИЗМЫ ПАТОГЕНЕЗА, КЛИНИЧЕСКИЕ ХАРАКТЕРИСТИКИ И ТРУДНОСТИ ЛЕЧЕНИЯ В УСЛОВИЯХ ПАНДЕМИИ
}

\section{ISCHEMIC STROKE AND COVID-19: PATHOGENESIS MECHANISMS, CLINICAL CHARACTERISTICS, AND TREATMENT DIFFICULTIES IN A PANDEMIC}

E. Vishneva

N. Vesnina

Summary. The emergence and spread of the new coronavirus infection (COVID-19) has caused the greatest public health problem. Current evidence suggests that COVID-19 can cause ischemic stroke, especially in severe disease, and there are similarities in the risk factors for severe COVID-19 as well as ischemic stroke, highlighting the complex relationship between the two conditions. The pandemic has created challenges for stroke care. The rapid assessment and timely interventions needed to achieve optimal outcomes in stroke treatment have been complicated by COVID-19 due to the need for infection prevention measures. The aim of this paper is to study the putative mechanisms of ischemic stroke in COVID-19 and the clinical characteristics of COVID-19 patients who develop ischemic stroke. The problems associated with the management of patients with ischemic stroke in the context of COVID-19 are highlighted, current treatment recommendations are considered, and potential areas for future research are revealed.

Keywords: coronavirus infection, ischemic stroke, patient, pandemic, COVID-19.

B озникновение и распространение высококонтагиозной новой коронавирусной инфекции (COVID-19) в конце 2019 года вызвало величайшую проблему общественного здравоохранения за последнее столетие. COVID-19 зарекомендовал себя, как самая серьезная вспышка инфекционного заболевания в новейшей истории, когда за первые пять месяцев было зарегистрировано более 6000000 подтвержденных случаев заболевания и более 300000 смертей. Хотя это заболевание считается первичным респираторным заболеванием, имеются данные о мультисистемном поражении, включая неврологические проявления [1]. Гипогевзия, аносмия, судороги и инсульт - это лишь часть из неврологических признаков заболевания,
Вишнева Елена Михайловна

Врач-кардиолог высшей категории, д.м.н., дочент, ФГБОУ ВО «Уральский Государственный Медицинский Университет»; главный врач, ООО «Семейная клиника», г. Екатеринбург e.m.vishneva@mail.ru

Веснина Наталья Сергеевна Врач-невролог, ГАУЗ СО «Городская клиническая больница № 14», г. Екатеринбург vesninans@mail.ru

Аннотация. Возникновение и распространение новой коронавирусной инфекции (COVID-19) вызвало величайшую проблему общественного здравоохранения. Текущие данные показывают, что COVID-19 может вызывать ишемический инсульт, особенно при тяжелом течении заболевания, есть сходства в факторах риска тяжелого COVID-19, а также ишемического инсульта, что подчеркивает сложную взаимосвязь между этими двумя состояниями. Пандемия создала проблемы для оказания помощи при инсульте. Быстрая оценка и своевременные вмешательства, необходимые для достижения оптимальных результатов в лечении инсульта, осложнились COVID-19 из-за необходимости принятия мер по профилактике инфекции. Целью данной статьи является изучение предполагаемых механизмов ишемического инсульта при COVID-19 и клинических характеристик пациентов c COVID-19, у которых развивается ишемический инсульт. Выделены проблемы, связанные с ведением больных ишемическим инсультом в условиях COVID-19, и рассматриваются текущие рекомендации по лечению, раскрыты потенциальные области для будущих исследований.

Ключевые слова: коронавирусная инфекция, ишемический инсульт, пациент, пандемия, COVID-19.

о которых сообщают врачи [2]. Хотя точная взаимосвязь между инсультом и COVID-19 все еще выявляется, появляется все больше подтверждений того, что заболевание может вызвать ишемический инсульт или усугубить уже существующий инсульт [3]. Факторы риска, такие как мужской пол, пожилой возраст и наличие сопутствующих заболеваний, таких как гипертоническая болезнь, диабет и сердечно-сосудистые заболевания, являются предикторами тяжелой формы COVID-19 [4]. Эти факторы также являются предрасполагающими к инсульту, что лежит в основе сложной взаимосвязи между этими двумя состояниями. Нынешняя пандемия имеет прямые и косвенные последствия для лечения инсульта. Пациенты, перенесшие инсульт, подвержены 
повышенному риску тяжелого заболевания при заражении COVID-19 [5]. Кроме того, пациенты с COVID-19, у которых развивается инсульт, подвергаются более высокому риску неблагоприятного исхода по сравнению с пациентами с инсультом без COVID-19 [6]. Таким образом, в данном литературном обзоре исследуются предполагаемые механизмы ишемического инсульта при COVID-19 и клинические характеристики инсульта у пациентов с COVID-19.

Вирус COVID19 - это коронавирус 2 типа острого респираторного синдрома (SARS-CoV-2), представляет собой оболочечный одноцепочечный вирус с положительной PHК семейства Coronaviridae, имеющий фосфолипидную двухслойную капсулу, содержащую белковые шипы [7]. SARS-CoV-2 получает доступ к организму благодаря взаимодействию его белкового шипа (S) и ангиотензин-превращающего фермента 2 (АПФ 2), обнаруженного во многих тканях, таких как легкие, почки, сердце и кишечник [7]. В последующем развивается клиника коагулопатии.

На сегодняшний день некоторые наблюдения показывают, что у пациентов с COVID-19 встречается повышенный риск тромбоэмболических осложнений. «Септическая коагулопатия» - термин, который возник, как признак тяжелого заболевания COVID-19 [8]. Это - более ранняя фаза ДВС-синдрома, характеризующаяся повышенным содержанием D-димера, удлиненным протромбиновым временем и низким количеством тромбоцитов, но, в отличие от ДВС-синдрома, при септической коагулопатии отсутствует гипофибриногенемия [9]. Затем следует синдром системного воспалительного ответа, вызванным иммунным ответом на вирус, приводящим к эндотелиальной дисфункции и тромбозу микроциркуляции [10]. Наблюдается чрезмерное подавление фибринолиза за счет увеличения выработки ингибитора активатора плазминогена-1, что увеличивает риск тромбоза [11]. В отличие от ДВС-синдрома, при септической коагулопатии нет кровотечений. Чаще у пациентов с COVID-19 встречается артериальный и венозный тромбоз [12].

Уже давно доказано, что наличие антифосфолипидных антител связано с протромботическим состоянием и формированием стойкой коагулопатии. По данным зарубежного исследования 56 пациентов с подтвержденным COVID-19, 14 пациентов имели положительный результат на волчаночный антикоагулянт, а у пяти были обнаружены антитела IgM или IgG к кардиолипину или ß2-гликопротеину-1 [13]. Доказано, что антифосфолипидные антитела связаны с артериальным и венозным тромбозом [10]. Однако, они так же часто обнаруживаются у здоровых людей, а повышенные уровни отмечаются так же и при других вирусных и бактериальных инфекциях [14]. До сих пор неясно, способствует ли присутствие антифосфолипидных антител у пациентов c COVID-19 коагулопатии или увеличивает риск ишемического инсульта.

Отдельного внимания заслуживает вопрос эндотелиальной дисфункции. Эндотелиальная дисфункция предрасполагает к образованию артериальных и венозных тромбозов. Нормальный эндотелий сосудов содержит про- и антитромботические факторы, которые обычно находятся в состоянии равновесия, чтобы предотвратить кровотечение или образование сгустков. Одним из возможных механизмов эндотелиальной дисфункции у пациентов с COVID-19 является истощение рецепторов АПФ2, которые обнаруживаются в эндотелиальных клетках сосудов [9]. Ренин-ангиотензин-альдостероновая система имеет классическую цепь рецепторов ренин/ АПФ1/ангиотензин II/ангиотензин II типа 1, которая играет физиологическую и патологическую роль в заболеваниях почек, кровеносных сосудов, сердца и головного мозга, а также АПФ2/ ангиотензин (1-7) / цепь рецептора сборки митохондрий (MasR), который был идентифицирован как негативный регулятор ангиотензина II [15]. Ренин продуцируется юкстагломерулярными клетками почек и превращает ангиотензиноген, продуцируемый печенью, в ангиотензин І. АПФ1 расщепляет ангиотензин I до ангиотензина II. Ангиотензин II, действуя через свои рецепторы, обладает вазопрессорным, провоспалительным и прокоагулянтным действием [9]. Было доказано, что ингибиторы рецепторов ангиотензина II обладают антигипертензивным, а также нейропротекторным действием [16]. АПФ2 противодействует действию АПФ1, превращая ангиотензин II в ангиотензин (1-7), сосудорасширяющую и противовоспалительную молекулу, и превращая ангиотензин I в ангиотензин (1-9), который далее превращается в ангиотензин (1-7) [17]. Ангиотензин (1-7) опосредует свое действие через рецептор MAS. Связываясь с АПФ2, SARS-CoV-2 индуцирует эндоцитоз рецептора, тем самым приводя к истощению «защитного» эндотелиального АПФ2 и смещая баланс в пользу АПФ1 и ангиотензина II, с усилением провоспалительной предрасположенности и повреждением эндотелия [9].

Другой возможный механизм повреждения эндотелия у пациентов с COVID-19 - это иммунная гиперреакция, известная как цитокиновый шторм [18]. Этот неконтролируемый и чрезмерный выброс цитокинов при COVID-19 был описан как основной фактор, вызывающий полиорганную дисфункцию [18]. Повышенные уровни цитокинов, таких как IL1- $\beta$, IL-7, IL-8, IL-9, IL-10, гранулоцитарно-макрофагальный колониестимулирующий фактор, IFN-ү, Фактор некроза-а (TNFa) были зарегистрирован при COVID-19 [19]. Воспалительные цитокины вызывают активацию эндотелия, повышен- 
ную экспрессию молекул адгезии эндотелиальных лейкоцитов, таких как молекула межклеточной адгезии 1, Е-селектин и молекула адгезии сосудистых клеток 1, которые взаимодействуют с рецепторами на поверхности лейкоцитов [20]. Эффект цитокинов и лейкоцит-опосредованное повреждение может нарушить целостность эндотелиальных клеток.

По данным некоторых источников сообщается, что повреждение сердца является одной из основных причин смерти при COVID-19 после респираторной дисфункции [21]. Было доказано, что повышенные маркеры сердечного повреждения, такие как тропонин I и тропонин T, креатининкиназа-MB, у пациентов с COVID-19 коррелируют с тяжестью заболевания [21]. Было высказано предположение, что прямое вирусно-опосредованное повреждение и эффект цитокинового шторма ответственны за повреждение сердца при COVID-19 [22]. Это проявляется острым миокардитом, перикардитом, аритмией, шоком и сердечной недостаточностью [22]. Дисфункция эндотелия сердца и аритмия увеличивают риск сердечной тромбоэмболии и инсульта. Роль этого в ишемическом инсульте при COVID-19 пока остается гипотетической.

В отношении проникновения вируса в центральную нервную систему для SARS-CoV-2 были предложены два потенциальных канала инвазии в ЦНС: гематогенное распространение в мозговой кровоток и передача через обонятельный эпителий через решетчатую пластинку в обонятельную луковицу [2]. Поскольку вирус присутствует в системном кровообращении, включая мозговое кровообращение, вялая церебральная микроциркуляция усиливает взаимодействие между вирусным шиповым белком и АПФ2 на церебральных эндотелиальных клетках [23]. Размножение и высвобождение вируса из эндотелиальных клеток может привести к повреждению эндотелия и обеспечить доступ вируса к мозгу [23]. Кроме того, рецепторы АПФ2 были обнаружены на нейронах и глиальных клетках, что делает их потенциальной мишенью для SARS-CoV-2 [24]. Наличие аносмии, гипогевзии и других неврологических проявлений у пациентов с COVID-19 подтверждают теорию прямого воздействия вируса на мозг [23].

Отсутствие эффективной вакцины или терапии от COVID-19 привело к испытаниям плазмы выздоравливающих для лечения тяжелобольных пациентов c COVID-19 [25]. Внутривенная терапия иммуноглобулинами использовалась как для профилактики, так и для лечения вирусных инфекций [25]. Однако такая терапия имеет потенциальные осложнения. Риск тромбоэмболии, связанной с внутривенным введением иммуноглобулинов, оценивается от 0,6 до 4,5\% [26]. Считается, что такие события, как инсульт, инфаркт миокарда, тромбоэмболия легочной артерии и тромбоз глубоких вен, вызваны повышением вязкости крови, вызванным иммунотерапией, тем самым предрасполагая к застою, что является фактором риска тромбообразования [26]. По данным одного из зарубежных исследований, среди 206 пациентов с тяжелым острым респираторным дистресс-синдромом у пяти пациентов развились церебральные инфаркты крупных артерий, причем три из них возникли у пациентов, получавших иммунотерапию [27]. Т.о., пациенты в критическом состоянии имеют повышенный риск тромбоза, поэтому применение иммунотерапии у этих пациентов может еще больше ухудшить риск тромбоэмболических событий.

Приведем результаты некоторых зарубежных исследований. В ретроспективном исследовании 3556 пациентов с COVID-19 в клинике Нью-Йорка у 32 (0,9\%) развился ишемический инсульт [6]. 65,6\% имели криптогенный инсульт, а 34,4\% соответствовали критериям эмболического инсульта с неустановленным источником. По сравнению с пациентами, перенесшими инсульт без COVID-19, пациенты с COVID-19 были старше (средний возраст 70 лет против 63 лет), имели более высокий балл по шкале Национального института здоровья (NIHSS) при поступлении (средний балл-19 против 8), повышенный уровень D-димера (> 10000 против 525 нг / мл), с большей вероятностью имели криптогенный инсульт (65,6\% против 34,4\%) и имели более высокий риск смертности в стационаре $(63,6 \%$ против 9,3\%). У 25 пациентов развился инсульт в течение 1-27 дней от начала заболевания, а у пяти ранее не было никаких симптомов.

Аналогичным образом было проведено одноцентровое ретроспективное исследование с участием 221 пациента c COVID-19, которое показало, что у 11 (5\%) развился ишемический инсульт, при этом у одного пациента развился тромбоз вен головного мозга, а у другого - кровоизлияние в мозг [28]. По сравнению с другими пациентами с COVID-19 без инсульта, те, у кого развился инсульт, были старше (средний возраст 72 против 52 лет) и имели более высокую частоту сопутствующих заболеваний, таких как гипертония, диабет, перенесенный инсульт в анамнезе, а также нарушение функции печени и почек. Так же было выявлено заболевание крупных артерий, заболевание средних сосудов и кардиоэмболические события.

Хотя инсульт чаще встречается у пожилых людей, так же есть сообщения об инсульте у более молодых пациентов, инфицированных COVID19. В ранее упомянутом исследовании вероятность инсульта была выше у молодых мужчин с повышенным уровнем тропонина в сыворотке по сравнению с контрольной группой в прошлом [6]. Так же Oxley и его коллеги сообщили 
о пяти случаях инсульта крупных сосудов у пациентов c COVID-19 моложе 50 лет [29]. Сосудистыми бассейнами, участвующими в данных случаях, были бассейн средней мозговой артерии (три случая), задняя мозговая артерия (один случай) и внутренняя сонная артерия (один случай) [29]. У троих из пяти пациентов наблюдаются симптомы COVID-19, у двух - бессимптомно. Аналогичным образом, в исследовании сообщалось о трех пациентах с COVID-19 с ишемическим инсультом крупных сосудов после субокклюзивного тяжелого стеноза общей сонной артерии с тромбозом, распространяющимся на проксимальную внутреннюю сонную артерию [30]. Возраст пациентов был 33, 55 и 77 лет. В другом исследовании сообщалось о случае 40-летнего пациента с COVID-19 с отрицательным результатом обследования на прокоагулянт, у которого развился ишемический инсульт крупных сосудов с поражением средней мозговой артерии [31]. Аналогичное сообщение об ишемическом инсульте крупных артерий было обнаружено у пяти из 206 пациентов с SARS в исследовании [27]. В этом исследовании четыре пациента были старше 50 лет (54-68), а пятому пациенту было 39 лет. Связь между ишемическим инсультом крупных артерий и COVID-19 у молодых пациентов до конца не изучена; предполагается, что у этих пациентов возникновение инсульта на фоне COVID19 может быть связано с гиперкоагуляцией.

В ретроспективном исследовании 214 пациентов c COVID-19 в Ухане, Китай, у 5,7\% развился инсульт. Эти данные были получены у пациентов с тяжелым течением заболевания [32]. Маркеры тяжелого течения COVID-19 включают лимфопению, лейкоцитоз, гипоальбуминемию, а также повышенные уровни аланинтрансаминазы, С-реактивного белка, ферритина, лактатдегидрогеназы и D-димера [33]. В исследовании, в котором сообщалось о шести пациентах с COVID-19, у которых развился ишемический инсульт, у всех пациентов была окклюзия крупных сосудов с заметно повышенным содержанием D-димеров. Волчаночные антикоагулянты, а также C-реактивный белок и ферритин были повышены у пяти пациентов [34]. Аналогичным образом, в исследовании четырех пациентов с ишемическим инсультом, у трех был повышенный уровень D-димера, а у двух - повышенный уровень C-реактивного белка [35].

Исход инсульта у пациентов с COVID-19 может отражать тяжесть заболевания. Оценка инсульта Национального института здоровья (NIHSS) использовалась для прогнозирования исхода инсульта. По сравнению с пациентами с инсультом, у которых не было COVID-19, пациенты с инсультом и COVID-19 имели более высокий балл по шкале NIHSS [6]. В исследовании Oxley с коллегами все пять пациентов с инсультом крупных сосудов имели оценку 13-23, что свидетельствует о более высоком риске неблагоприятного исхода заболевания [29]. Аналогичным образом, в ретроспективном исследовании шести пациентов с COVID-19, перенесших инсульт, пятеро умерли, а у одного был стойкий тяжелый неврологический дефицит [36].

COVID-19 прямо или косвенно влияет на тактику ведения больных с инсультом. С момента вспышки заболевания для борьбы с этой инфекцией было принято множество мер, таких как меры самоизоляции, приостановка плановых процедур и обычных амбулаторных клиник, плановых госпитализаций [37]. По данным Всемирной организации по инсульту, многие страны столкнулись с перегрузкой больниц, что привело к перераспределению неврологических и инсультных коек, а также отделений интенсивной терапии (ОИТ), предназначенных для лечения инсульта, для ухода за пациентами с COVID-19 [3]. Кроме того, во многих больницах произошло переключение врачей и среднего медицинского персонала, занимающихся инсультом, на лечение COVID-19 [38]. Следствием этого является снижение способности оказывать необходимую помощь пациентам с инсультом. Исследование с участием 280 центров в Китае показывает, что количество госпитализаций по поводу инсульта снизилось на 40\%, а количество случаев тромболизиса и тромбэктомии снизилось на 25\% в феврале 2020 года по сравнению с февралем 2019 года [39]. Такое сокращение случаев госпитализации после инсульта может быть связано с тем, что пациенты предпочитают оставаться дома из-за страха заразиться вирусом в больнице. Из вышеизложенного следует, что на сегодняшний день на первый план встает отсроченное начало лечения инсульта, т.к. пациенты пропускают терапевтическое окно и, как следствие, возрастают риски инвалидизации [3].

Риск заражения COVID-19 увеличивается среди медицинских работников, которые контактируют с инфицированными пациентами. Во всем мире были сообщения о заражении COVID-19 и смерти врачей, а так же среднего и младшего медицинского персонала [38]. Это требует дополнительных мер защиты, использования средств индивидуальной защиты, которых в некоторых странах часто не хватает. Инфекция среди членов специализированных бригад по оказанию помощи при инсульте, которых также не хватает из-за перераспределения, может привести к карантину, что еще больше истощит человеческие ресурсы, доступные для оказания помощи при инсульте.

До нынешней глобальной пандемии были разработаны и повсеместно приняты руководства по лечению инсульта для медицинских работников, участвующих в лечении инсульта [40]. Одним из таких рекоменда- 
ций является руководство по ведению ишемического инсульта, разработанное Американской кардиологической ассоциацией / Американской ассоциацией инсульта (AHA / ASA) [40]. В этом документе представлены рекомендации по догоспитальному ведению инсульта, неотложной оценки и лечения, а также по общей поддерживающей терапии. Из-за того, что развитие ишемического инсульта зависит от времени возникновения первых симптомов, в текущих руководствах по инсульту рекомендуется быстро оказывать неотложную помощь, избегая при этом ненужных затрат времени на лечение [41]. Во всех случаях больному с подозрением на инсульт следует незамедлительно сделать снимки головного мозга по прибытии в больницу, предпочтительно в течение 20 минут после прибытия в приемный покой [40]. Пациенты с инсультом, которые соответствуют критериям, должны подвергаться быстрому проведению процедуры тромболизиса с использованием рекомбинантного тканевого активатора плазминогена (альтеплаза) и / или механической тромбэктомии у пациентов с окклюзией крупных сосудов. Данные процедуры следует проводить в кратчайшие сроки, чтобы ограничить повреждение головного мозга [41]. Этот процесс лечения инсульта осложнился с момента появления COVID-19. Американская кардиологическая ассоциация / Американская ассоциация инсульта также выпустила временное руководство по ведению пациентов с инсультом у пациентов с COVID-19 [44].

Независимо от того, поступает ли новый пациент в приемное отделение или уже поступил в больницу, все пациенты с инсультом проходят первоначальную быструю оценку. В настоящее время этот рутинный процесс осложняется COVID-19, поэтому необходимо учитывать инфекционный статус пациента. Описаны три категории пациентов с инсультом, инфицированных COVID-19, которые следует быстро определить во время первоначальной оценки: пациенты с известной инфекцией, которые обычно находятся на поздней стадии заболевания, пациенты с подозрением на COVID-19 инфекцию, основанную на симптомах болезни в анамнезе, контактах с инфицированными людьми, месте жительства или поездках в районы высокого риска, и бессимптомных, без контактов с инфицированными людьми или проживания в зонах высокого риска [42]. Пациентов, у которых есть подозрение или подтвержденная инфекция, следует немедленно отделить. По возможности, эта маршрутизация должна быть проведена службами неотложной медицинской помощи до прибытия в приемное отделение [41]. Однако многие пациенты с инсультом могут быть дезориентированы, у них могут быть речевые нарушения или они могут быть без сознания, что затрудняет попытки определить риск инфекции. Кроме того, бессимптомные люди могут быть распространителями болезней. Таким образом, важно иметь настороженность в отношении каждой категории пациентов. Это обеспечит принятие необходимых защитных мер медицинским персоналом. Принимая во внимание неотложный характер оказания помощи при инсульте и временные рамки, необходимые для получения подтверждающего результата теста для пациентов с COVID-19, следует применять меры профилактики передачи заболевания, такие как использование средств индивидуальной защиты (СИЗ), мытье рук и меры социального дистанцирования, которые используются во время первичной оценки [42]. Если возможно, следует рассмотреть возможность дистанционной оценки с использованием телемедицинской консультации $[40,45]$. Это позволит дистанционно оценивать нейровизуализационные изображения, а также проводить неврологическое обследование с помощью видео, тем самым ограничивая воздействие как на медицинских работников, так и на пациентов [41]. По сравнению с обследованием у постели больного, телеконсультация показала свою эффективность при оценке баллов по шкале NIHSS, а также при оценке соответствия критериям тромболизиса и тромбэктомии [45].

Результат исхода инсульта при COVID-19 может коррелировать с тяжестью основного заболевания. Доказано, что уровень смертности у пациентов с инсультом и COVID-19 выше, чем у пациентов без COVID-19 [29, 36]. Поэтому важно оценить предикторы повышенной внутрибольничной смертности. Эти факторы включают пожилой возраст, сердечно-сосудистые заболевания, острое повреждение почек, высокий показатель оценки полиорганной недостаточности (SOFA), гипоальбуминемию и повышенные уровни трансаминазы, лактатдегидрогеназы, ферритина, D-димера и C-реактивного белка [33]. Оценка SOFA используется в качестве индекса тяжести состояния у тяжелобольных, а также для прогнозирования риска смерти. Эта оценка полиорганной дисфункции важна для определения прогноза заболевания при рассмотрении соответствующего плана лечения инсульта [42].

B отношении диагностики рекомендации $\mathrm{AHA} /$ ASA рекомендуют экстренную визуализацию мозга, желательно в течение 20 минут после прибытия в приемное отделение. Пациентам с окклюзией крупных сосудов, которые соответствуют критериям тромбэктомии, требуется компьютерная томографическая ангиография или перфузионная КТ в зависимости от времени от начала заболевания до проявления симптомов [40]. В данном руководстве рекомендуется проводить введение контрастного вещества после определения уровня креатинина в сыворотке крови [40]. У пациентов с COVID-19 и инсультом высок риск острого повреждения почек. Введение контрастного вещества 
может спровоцировать острое повреждение почек, тем самым увеличивая смертность. Следует соблюдать осторожность при использовании контрастных исследований у пациентов с COVID-19, перенесших инсульт, и следует учитывать соотношение общего риска и пользы [42]. Так же необходимо рассмотреть возможность проведения компьютерной томографии грудной клетки вместе с нейроваскулярной визуализацией, поскольку это даст представление о степени поражения легких [41]. Там, где это возможно, должен быть создан отдельный рентгенологический кабинет, предназначенный для пациентов с подтвержденным или высоким риском COVID-19 [41].

Текущие рекомендации рекомендуют начинать внутривенный тромболизис с помощью rt-PA в течение 3 часов после начала инсульта и в течение 3-4,5 часов у отдельных пациентов [40]. Дисфункция печени, проявляющаяся повышенным уровнем трансаминаз, а также коагулопатия, документированы как аномалии при COVID-19 [33]. Нарушение функции печени при COVID-19 может происходить с коагулопатией или без нее [42]. У этих пациентов следует рассмотреть возможность оценки гемостатических характеристик с помощью таких тестов, как тромбоэластография, и определения уровня D-димера в сыворотке [42]. Хотя влияние дисфункции печени на метаболизм rt-PA у пациентов с COVID-19 на данный момент неясно, существует потенциальный риск лекарственной токсичности при нарушении метаболизма в печени. Об этом следует помнить мультидисциплинарным бригадам по лечению инсульта.

В текущих рекомендациях отдается преимущество механической тромбэктомии, выполненной в течение 6 часов после начала инсульта, у пациентов с окклюзией крупных сосудов, баллов по шкале NIHSS $\geq 6$ и у которых нет обширной ишемии при КТ [40]. Отобранные пациенты с инсультом в пределах 6-16 часов после последнего известного нормального состояния и пациенты в течение 6-24 часов, которые прошли КТ-исследования перфузии или МРТ, также считаются подходящими для тромбэктомии [40]. Специализированная помощь, необходимая для тромбэктомии, может потребовать перевода пациента в другое учреждение, что может быть осложнено дополнительными проблемами маршрутизации из-за COVID-19 [42]. Стандартные протоколы предосторожности, такие как использование СИЗ, должны соблюдаться в ангиографических кабинетах во время механической тромбэктомии, чтобы снизить риск заражения среди медицинского персонала [41].

Ишемические инсульты являются осложнениями COVID-19 наряду с коагулопатией, эндотелиальной дисфункцией, кардиоэмболией и прямым вирусно-опосредованным повреждением нейронов в качестве возможных основных причин. Пожилые пациенты с тяжелым заболеванием подвержены более высокому риску этого осложнения, однако окклюзия крупных сосудов обычно наблюдается у более молодых пациентов. Быстрая оценка и вмешательство, необходимые для получения оптимальных результатов при лечении острейшего периода инсульта, осложняются COVID-19. Необходимо принимать меры инфекционного контроля, обеспечивая при этом адекватный уход за такими пациентами. Существует необходимость в дополнительных исследованиях, чтобы лучше понять, каким образом COVID-19 вызывает инсульт, и какая существует взаимосвязь между инсультом крупных сосудов и пациентами молодого возраста. Кроме того, следует изучить преимущества использования антикоагулянтов для профилактики и лечения инсульта у пациентов с COVID-19.

\section{ЛИТЕРАТУРА}

1. H.R. Niazkar, B. Zibaee, A. Nasimi, and N. Bahri, “The neurological manifestations of COVID-19: a review article," Neurological Sciences, vol. 41, no. 7, pp. 1-5, 2020.View at: Publisher Site | Google Scholar

2. V. Montalvan, J. Lee, T. Bueso, J. De Toledo, and K. Rivas, "Neurological manifestations of COVID-19 and other coronavirus infections: a systematic review," Clinical Neurology and Neurosurgery, vol. 194, Article ID105921, 2020.View at: Publisher Site | Google Scholar

3. H.S. Markus and M. Brainin, "COVID-19 and stroke-a global world stroke organization perspective," International Journal of Stroke, vol. 15, no. 4, p. 361, 2020. View at: Publisher Site |Google Scholar

4. F. Zhou, T. Yu, R. Du et al., "Clinical course and risk factors for mortality of adult inpatients with COVID-19 in Wuhan, China: a retrospective cohort study," The Lancet, vol. 395, Article ID10229, pp. 1054-1062, 2020.View at: Publisher Site | Google Scholar

5. G. Aggarwal, G. Lippi, and B. Michael Henry, "Cerebrovascular disease is associated with an increased disease severity in patients with coronavirus disease 2019 (COVID-19): a pooled analysis of published literature," International Journal of Stroke, vol. 15, no. 4, p. 385, 2020.View at: Publisher Site |Google Scholar

6. S. Yaghi, K. Ishida, J. Torres et al., "SARS2-COV-2 and stroke in a new york healthcare system," Stroke, vol. 20, 2020.View at: Publisher Site | Google Scholar

7. R. Lu, X. Zhao, J. Li et al., "Genomic characterisation and epidemiology of 2019 novel coronavirus: implications for virus origins and receptor binding," The Lancet, vol. 395, no. 10224, p. 565, 2020.View at: Publisher Site | Google Scholar

8. N. Tang, H. Bai, X. Chen, J. Gong, D. Li, and Z. Sun, “Anticoagulant treatment is associated with decreased mortality in severe coronavirus disease 2019 patients with coagulopathy," Journal of Thrombosis and Haemostasis, vol. 18, no. 5, p. 1094, 2020.View at: Publisher Site | Google Scholar 
9. D.C. Hess, W. Eldahshan, and E. Rutkowski, "COVID-19-related stroke,"Translational Stroke Research, vol. 11, no. 3, p. 322, 2020.View at: Publisher Site |Google Scholar

10. T. Iba, J.H. Levy, T.E. Warkentin, J. Thachil, T. Poll, and M. Levi, "Diagnosis and management of sepsis-induced coagulopathy and disseminated intravascular coagulation," Journal of Thrombosis and Haemostasis, vol. 17, no. 11, p. 1989, 2019.View at: Publisher Site | Google Scholar

11. K. Koyama, S. Madoiwa, S. Nunomiya et al., "Combination of thrombin-antithrombin complex, plasminogen activator inhibitor-1, and protein C activity for early identification of severe coagulopathy in initial phase of sepsis: a prospective observational study," Critical Care, vol. 18, no. 1, p. R13, 2014.View at: Publisher Site | Google Scholar

12. F.A. Klok, M.J. H.A. Kruip, N.J.M. Van Der Meer et al., "Incidence of thrombotic complications in critically ill ICU patients with COVID-19," Thrombosis Research, vol. 191, p. 145, 2020.View at: Publisher Site | Google Scholar

13. I. Harzallah, A. Debliquis, and B. Drénou, "Lupus anticoagulant is frequent in patients with Covid-19," Journal of Thrombosis and Haemostasis, vol. 18, no. 8, p. 2064, 2020.View at: Publisher Site | Google Scholar

14. R.A. Asherson and R. Cervera, "Antiphospholipid antibodies and infections," Annals of the Rheumatic Diseases, vol. 62, no. 5, p. 388, 2003.View at: Publisher Site | Google Scholar

15. J. Xu, J. Fan, F. Wu et al., "The ACE2/angiotensin-(1-7)/Mas receptor axis: pleiotropic roles in cancer," Frontiers in Physiology, vol. 8, p. 276, 2017.View at: Publisher Site | Google Scholar

16. M. Padma, "Angiotensin-converting enzyme inhibitors will help in improving stroke outcome if given immediately after stroke," Annals of Indian Academy of Neurology, vol. 13, no. 3, p. 156, 2010.View at: Publisher Site | Google Scholar

17. A.P. Mecca, R.W. Regenhardt, T.E. O'Connor et al., "Cerebroprotection by angiotensin-(1-7) in endothelin-1-induced ischaemic stroke," Experimental Physiology, vol. 96, no. 10, p. 1084, 2011.View at: Publisher Site |Google Scholar

18. P. Mehta, D.F. McAuley, M. Brown, E. Sanchez, R.S. Tattersall, and J.J. Manson, "COVID-19: consider cytokine storm syndromes and immunosuppression," The Lancet, vol. 395, no. 10229, pp. 1033-1034, 2020.View at: Publisher Site | Google Scholar

19. C. Huang, Y. Wang, X. Li et al., "Clinical features of patients infected with 2019 novel coronavirus in Wuhan, China,"The Lancet, vol. 395, no. 10223, pp. 497-506, 2020.View at: Publisher Site | Google Scholar

20. C. Zhang, "The role of inflammatory cytokines in endothelial dysfunction," Basic Research in Cardiology, vol. 103, no. 5, p. 398, 2008.View at: Publisher Site | Google Scholar

21. Q. Ruan, K. Yang, W. Wang, L. Jiang, and J. Song, "Clinical predictors of mortality due to COVID-19 based on an analysis of data of 150 patients from Wuhan, China," Intensive Care Medicine, vol. 46, no. 5, pp. 846-848, 2020.View at: Publisher Site | Google Scholar

22. A. Akhmerov and E. Marbán, "COVID-19 and the heart," Circulation Research, vol. 126, no. 10, p. 1443, 2020.View at: Publisher Site |Google Scholar

23. A.M. Baig, A. Khaleeq, U. Ali, and H. Syeda, "Evidence of the COVID-19 virus targeting the CNS: tissue distribution, host-virus interaction, and proposed neurotropic mechanisms," ACS Chemical Neuroscience, vol. 11, no. 7, p. 995, 2020.View at: Publisher Site | Google Scholar

24. J. Netland, D.K. Meyerholz, S. Moore, M. Cassell, and S. Perlman, "Severe acute respiratory syndrome coronavirus infection causes neuronal death in the absence of encephalitis in mice transgenic for human ACE2," Journal of Virology, vol. 82, no. 15, p. 7264, 2008.View at: Publisher Site | Google Scholar

25. E.M. Bloch, S. Shoham, A. Casadevall et al., "Deployment of convalescent plasma for the prevention and treatment of COVID-19," Journal of Clinical Investigation, vol. 130, no. 6, p. 2757, 2020.View at: Publisher Site | Google Scholar

26. J.B. Caress, M.S. Cartwright, P.D. Donofrio, and J.E. Peacock, "The clinical features of 16 cases of stroke associated with administration of IVIg," Neurology, vol. 60, no. 11, p. 1822, 2003. View at: Publisher Site | Google Scholar

27. T. Umapathi, A.C. Kor, N. Venketasubramanian et al., "Large artery ischaemic stroke in severe acute respiratory syndrome (SARS)," Journal of Neurology, vol. 251, no. 10, p. 1227, 2004.View at: Publisher Site | Google Scholar

28. Y. Li, M. Wang, Y. Zhou et al., "Acute cerebrovascular disease following COVID-19: a single center, retrospective, observational study," Neurology, vol. 5, no. 3, pp. 279-284, 2020, https://www.ncbi.nlm.nih.gov/pmc/articles/PMC7371480/.View at: Publisher Site | Google Scholar

29. T.J. Oxley, J. Mocco, S. Majidi et al., "Large-vessel stroke as a presenting feature of covid-19 in the young," New England Journal of Medicine, vol. 382, no. 20, p. e60, 2020.View at: Publisher Site | Google Scholar

30. M.G. Fara, L.K. Stein, M. Skliut, S. Morgello, J.T. Fifi, and M.S. Dhamoon, "Macrothrombosis and stroke in patients with mild Covid-19 infection," Journal of Thrombosis and Haemostasis, vol. 18, no. 8, p. 2031, 2020.View at: Publisher Site | Google Scholar

31. K. Gunasekaran, K. Amoah, V. Rajasurya, and M.G. Buscher, "Stroke in a young COVID-19 patient," An International Journal of Medicine, vol. 8, 2020.View at: Publisher Site | Google Scholar

32. L. Mao, H. Jin, M. Wang et al., "Neurologic manifestations of hospitalized patients with coronavirus disease 2019 in Wuhan, China," JAMA Neurology, vol. 77 , no. 6, Article ID e201127, p. 683, 2020.View at: Publisher Site | Google Scholar

33. G. Chen, D. Wu, W. Guo et al., "Clinical and immunological features of severe and moderate coronavirus disease 2019," Journal of Clinical Investigation, vol. 130, no. 5, p. 2620, 2020.View at: Publisher Site | Google Scholar

34. R. Beyrouti, M.E. Adams, L. Benjamin et al., "Characteristics of ischaemic stroke associated with COVID-19," Journal of Neurology, Neurosurgery \& Psychiatry, vol. 91, no. 8, pp. 889-891, 2020.View at: Publisher Site | Google Scholar

35. A. Tunç, Y. Ünlübaş, M. Alemdar, and E. Akyüz, "Coexistence of COVID-19 and acute ischemic stroke report of four cases," Journal of Clinical Neuroscience, vol. 77, no. 20, pp. 227-229, 2020.View at: Publisher Site | Google Scholar

36. M. Morassi, D. Bagatto, M. Cobelli et al., "Stroke in patients with SARS-CoV-2 infection: case series," Journal of Neurology, vol. 267, no. 8, p. 2185, 2020.View at: Publisher Site | Google Scholar 
37. J. Zhao, A. Rudd, and R. Liu, "Challenges and potential solutions of stroke care during the coronavirus disease 2019 (COVID-19) outbreak," Stroke, vol. 51, no. 5, p. 1356, 2020.View at: Publisher Site | Google Scholar

38. E. Kursumovic, S. Lennane, and T.M. Cook, "Deaths in healthcare workers due to covid-19: the need for robust data and analysis," Anaesthesia, vol. 18, 2020. View at: Publisher Site | Google Scholar

39. J. Zhao, H. Li, D. Kung, M. Fisher, Y. Shen, and R. Liu, "Impact of the COVID-19 epidemic on stroke care and potential solutions," Stroke, vol. 43, 2020.View at: Publisher Site | Google Scholar

40. W.J. Powers, A.A. Rabinstein, T. Ackerson et al., "Guidelines for the early management of patients with acute ischemic stroke: 2019 update to the 2018 guidelines for the early management of acute ischemic stroke: a guideline for healthcare professionals from the American Heart Association/American Stroke Association," Stroke, vol. 50, no. 12, pp. e440-e441, 2019.View at: Publisher Site | Google Scholar

41. A. Pedicelli, I. Valente, F. Pilato, M. Distefano, and C. Colosimo, "Stroke priorities during COVID-19 outbreak: acting both fast and safe," Journal of Stroke and Cerebrovascular Diseases, vol. 29, no. 8, p. 104922, 2020.View at: Publisher Site |Google Scholar

42. A.I. Qureshi, F. Abd-Allah, F. Al-Senani et al., "Management of acute ischemic stroke in patients with COVID-19 infection: report of an international panel," International Journal of Stroke, vol. 15, no. 5, p. 540, 2020.View at: Publisher Site | Google Scholar

43. M. Aggour, P. White, Z. Kulcsar, J. Fiehler, and P. Brouwer, "European Society of Minimally Invasive Neurological Therapy (ESMINT) recommendations for optimal interventional neurovascular management in the COVID-19 era," Journal of Neurolnterventional Surgery, vol. 12, no. 6, p. 542, 2020.View at: Publisher Site I Google Scholar

44. AHA/ASA Stroke Council Leadership, "Temporary emergency guidance to US stroke centers during the coronavirus disease 2019 (COVID-19) pandemic: on behalf of the American Heart Association/American Stroke Association Stroke Council Leadership," Stroke, vol. 51, no. 6, pp. 1910-1912, 2020.View at: Publisher Site | Google Scholar

45. G.S. Silva and L.H. Schwamm, "Use of telemedicine and other strategies to increase the number of patients that may be treated with intravenous thrombolysis," Current Neurology and Neuroscience Reports, vol. 12, no. 1, pp. 10-16, 2012.View at: Publisher Site | Google Scholar

46. P.-J. Hsu, C.-H. Chen, S.-J. Yeh, L.-K. Tsai, S.-C. Tang, and J.-S. Jeng, "High plasma D-dimer indicates unfavorable outcome of acute ischemic stroke patients receiving intravenous thrombolysis," Cerebrovascular Diseases, vol. 42, no. 1-2, p. 117, 2016.View at: Publisher Site | Google Scholar

47. T. Emiru, S.A. Chaudhry, and A.I. Qureshi, "A survey of preprocedural intubation practices for endovascular treatment of acute ischemic stroke," Journal of Vascular and Interventional Neurology, vol. 7, no. 3, pp. 30-33, 2014.View at: Google Scholar

( В Вишнева Елена Михайловна ( e.m.vishneva@mail.ru ), Веснина Наталья Сергеевна ( vesninans@mail.ru ).

Журнал «Современная наука: актуальные проблемы теории и практики»

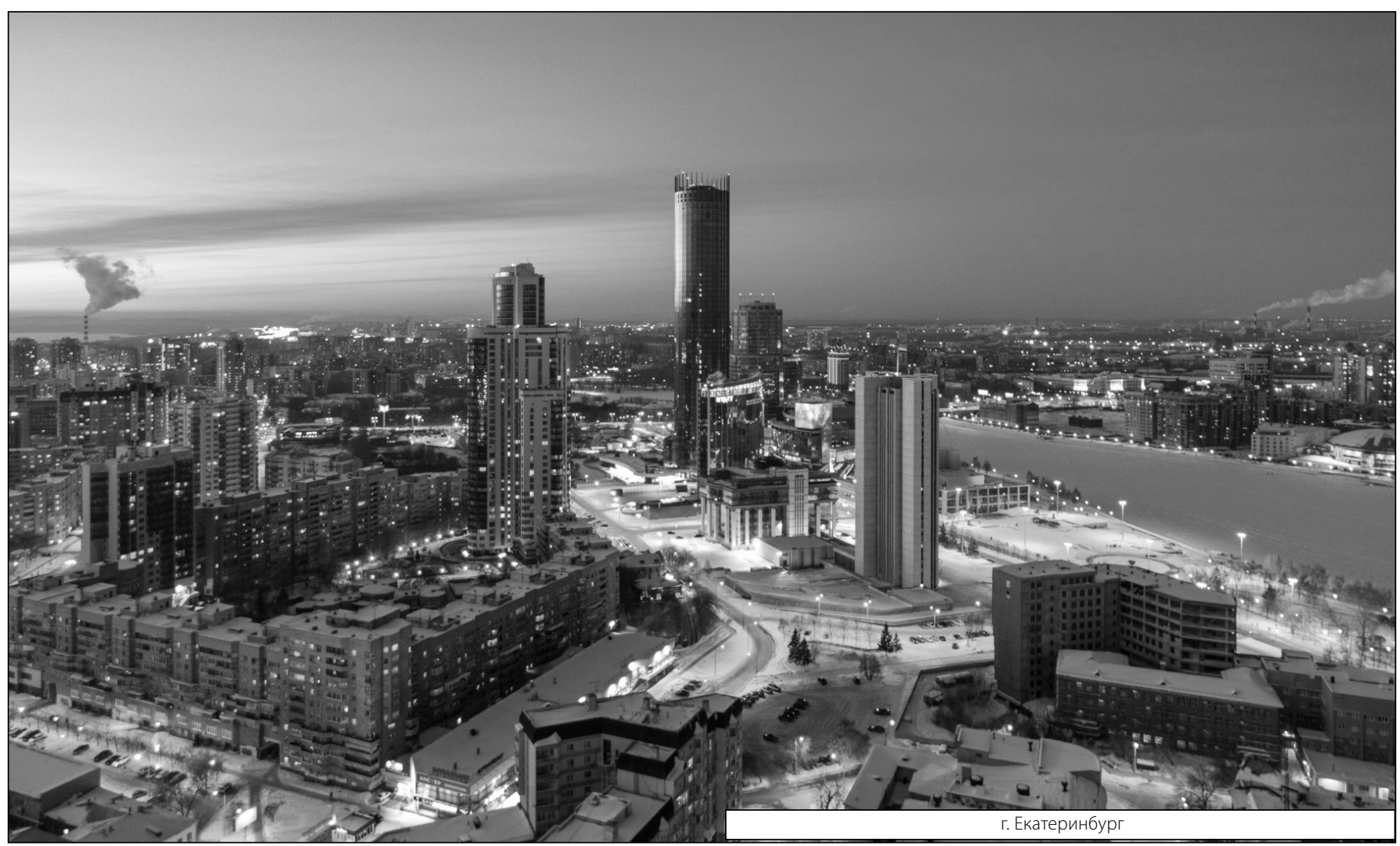

